\title{
Enhanced morphological diagnosis in infective endocarditis by transoesophageal echocardiography
}

Meindert A Taams, Elma J Gussenhoven, Egbert Bos, Peter de Jaegere, Jos R T C Roelandt, George R Sutherland, Nicolaas Bom

\begin{abstract}
Thirty three consecutive patients with clinically suspected endocarditis were studied by both precordial cross sectional echocardiography and transoesophageal echocardiography. The diagnostic value of both techniques was assessed. The data were compared with findings at operation in 25 patients. In 21 patients with native valve endocarditis precordial echocardiography showed evidence of vegetations in six patients and suggested their presence in nine. Transoesophageal echocardiography identified vegetations in 18 patients. Complications were seen in four patients at precordial echocardiography and in nine patients at transoesophageal echocardiography. Precordial echocardiography did not show vegetations in any of the 12 patients with prosthetic valve endocarditis whereas transoesophageal echocardiography showed vegetations in four. Complications were seen in four patients at precordial echocardiography and in 10 at transoesophageal echocardiography. Echocardiographic findings were confirmed at operation in all 25 operated patients. In two patients both echocardiographic techniques had missed the perforation of the cusps of the aortic valve that was seen at operation, but this had no effect on patient management. Transoesophageal echocardiography is the best diagnostic approach when infective endocarditis is suspected in patients with either native or prosthetic valves.
\end{abstract}

Before the introduction of transoesophageal echocardiography, high resolution precordial cross sectional echocardiography was widely accepted as a valuable method of diagnosing infective endocarditis. But this method has limitations, and false positive $e^{1-3}$ as well as false negative diagnoses have been reported in patients who eventually required operation. ${ }^{4-6}$ In patients with a prosthetic valve precordial echocardiography is hampered because the prosthesis interferes with the ultrasound beam. $^{7-9}$ Cardiac catheterisation is of limited value in such patients. ${ }^{610}$ The introduction of transoesophageal echocardiography provided an alternative diagnostic approach. ${ }^{11-1}$

We assessed the diagnostic value of transoesophageal echocardiography in identifying abnormalities caused by infective endocarditis. The results were compared with the findings at precordial echocardiography and at operation.

\section{Patients and methods}

STUDY GROUP

Over a 4 year period (1984-1988) 33 consecutive patients ( 24 men and nine women; mean age 45 , range 18-81) with clinically suspected infective endocarditis were investigated by precordial echocardiography and subsequently by transoesophageal echocardiography (the interval between studies was $<3$ days).

The clinical diagnosis of infective endocarditis was supported by bacteriological findings (32 patients had positive blood cultures) and surgical description (25 patients). Indications for cardiac surgery were: congestive cardiac failure (15 patients); persistent fever (five patients); multiple embolism (one patient); and endocarditis during the waiting period for elective cardiac surgery in our unit (four patients)

Twenty one patients had endocarditis of a native valve (12 mitral and nine aortic). The underlying valve disease was mitral stenosis in two, mitral valve myxomatous degeneration in three, and bicuspid aortic valve in four patients (tables 1 and 2). Operation was performed within 16 days at the transoesophageal echocardiographic study in 15 patients (range 1-16 days). The six unoperated patients were successfully treated with antibiotics.

Twelve patients were referred with prosthetic valve endocarditis. The prostheses implanted included two mitral; six aortic, mitral and aortic in one; and mitral, aortic, and tricuspid in three (table 3). Operation was performed in 10 patients within seven days of the transoesophageal echocardiographic study (range 1-7 days). One patient died and necropsy was not performed. One patient was treated successfully with antibiotics.

\section{EQUIPMENT AND TECHNIQUES}

We performed precordial cross sectional echocardiographic studies with a Toshiba SSH-65A, Toshiba SH 160, or HewlettPackard HP 77020 AC imaging system. The frequency of the transducers used was 3.5, 3.75 , or $5 \mathrm{MHz}$ respectively.

The transoesophageal study was performed with a $5.6 \mathrm{MHz}$ phased array transducer mounted at the tip of a gastroscope tube. The 
Table 1 Detection of vegetations or complications or both in patients with mitral valve endocarditis

\begin{tabular}{|c|c|c|c|c|c|}
\hline \multirow{2}{*}{$\begin{array}{l}\text { Native mitral valve } \\
\text { Patient no }\end{array}$} & \multicolumn{2}{|c|}{ Precordial echocardiography } & \multicolumn{2}{|c|}{ Transoesophageal echocardiography } & \multirow[b]{2}{*}{ Operation } \\
\hline & Vegetations & Complications & Vegetations & Complications & \\
\hline $\begin{array}{l}1 \\
2 \\
3 \\
4 \mathrm{MD} \\
5 \\
6 \\
7 \mathrm{MS} \\
8 \mathrm{MS} \\
9 \\
10 \mathrm{MD} \\
11 \mathrm{MD} \\
12(\mathrm{fig} 3)\end{array}$ & $\begin{array}{l}- \\
- \\
? \\
? \\
? \\
? \\
? \\
? \\
+ \\
+ \\
+ \\
+\end{array}$ & $\begin{array}{l}- \\
- \\
- \\
- \\
- \\
- \\
- \\
- \\
- \\
\overline{-} \\
\text { Abnormal MV }\end{array}$ & $\begin{array}{l}+ \\
- \\
- \\
+ \\
+ \\
+ \\
+ \\
+ \\
+ \\
+ \\
+ \\
+\end{array}$ & $\begin{array}{l}\overline{\text { MV }} \\
\text { MV cordal rupture } \\
\overline{-} \\
\text { MV cordal rupture } \\
\text { MV cordal rupture } \\
- \\
- \\
- \\
- \\
\overline{-} \\
\text { Mycotic aneurysm } \\
\text { MV and fistula }\end{array}$ & $\begin{array}{l}\mathrm{NP} \\
\mathrm{P} \\
\mathrm{P} \\
\mathrm{P} \\
\mathrm{P} \\
\mathrm{P} \\
\mathrm{NP} \\
\mathrm{P} \\
\mathrm{NP} \\
\mathrm{NP} \\
\mathrm{NP} \\
\mathrm{P}\end{array}$ \\
\hline
\end{tabular}

$\mathrm{MD}$, myxomatous degeneration; $\mathrm{MV}$, mitral valve; $M S$, mitral stenosis; $\mathrm{P}$, performed; NP, not performed.

transducer was interfaced with a HewlettPackard imaging system (HP 77020 AC). All patients fasted for at least 4 hours. Premedication was not given and local anaesthetic $(10 \%$ lignocaine) was sprayed into the patient's hypopharynx. ${ }^{14}$ In the last 23 patients the tube was wrapped in a disposable sheath (International Medical) before the procedure. This did not cause any problems or image deterioration. An imaginary three dimensional outline of the defect was obtained from cross sections taken in different planes after careful tilting and repositioning of the transducer.

\section{DEFINITION OF LESION}

$A$ vegetation was defined as a localised mobile mass of echoes contiguous with a valve leaflet or prosthetic valve (figs 1 and 2).

Cordal rupture was defined as a systolic whipping motion of an affected mitral leaflet tip within the left atrial cavity with loss of normal leaflet apposition.

Cusp perforation was recognised as an interruption of echoes in an aortic cusp (fig 2) or Hancock valve (see fig 4).

Abscess was defined as an abnormal echolucent area within the perivalvar tissue without communication with the circulation.

Mycotic aneurysm presented as an abnormal pulsatile echo-free protusion that was annular, supra-annular, or subannular (figs 1, 3, and 4). Valve dehiscence presented as an echolucent area seen around the prosthetic valve ring resulting in open communication between two adjacent cavities (fig 1 ).

\section{Results}

Tables 1-3 summarise the findings at precordial and transoesophageal echocardiography and at operation.

NATIVe Mitral VAlve (I2 Patients, TABLE I) Precordial echocardiography did not show a defect related to infective endocarditis in two 음 patients. In six patients the images suggested the possibility of vegetations. Vegetations were $\pi$ positively identified in three patients. In one patient (case 12) the mitral valve was abnormal. Transoesophageal echocardiography showed valve abnormalities in all 12 patients, vegetations in nine, and complications in five. These data were confirmed at operation in seven patients. Five patients were successfully treated with antibiotics.

NATIVE AORTIC VALVE (NINE PATIENTS, TABLE 2) Precordial echocardiographic studies did not show a defect in three patients. Vegetations 3 were suspected in three patients and were definitely seen in three other patients. Signs of a complex abnormality were seen in three patients (patients 7-9).

Transoesophageal echocardiography iden- $\frac{0}{3}$ tified the valve defect in all nine patients. Vegetations were seen in all and additional complications were identified in four (patients

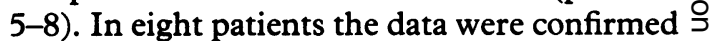
at operation. The remaining patient (case 6) $\frac{D}{0}$ was successfully treated with antibiotics. The additional feature of perforation of the aortic $\mathcal{N}$ cusp was missed in two patients with one or $N$ both techniques (patients 4,5 , and 9 ).

Table 2 Detection of vegetations or complications or both in patients with aortic valve endocarditis

\begin{tabular}{|c|c|c|c|c|c|}
\hline \multirow{2}{*}{$\begin{array}{l}\text { Native aortic valve } \\
\text { Patient no }\end{array}$} & \multicolumn{2}{|c|}{ Precordial echocardiography } & \multicolumn{2}{|c|}{ Transoesophageal echocardiography } & \multirow[b]{2}{*}{ Operation } \\
\hline & Vegetations & Complications & Vegetations & Complications & \\
\hline 1 & - & - & + & - & $\mathbf{P}$ \\
\hline 2 & - & - & $\begin{array}{ll}T \\
+\end{array}$ & - & $\mathbf{P}$ \\
\hline 3 bicuspid & - & - & + & - & $\mathbf{P}$ \\
\hline & ? & $\star$ & + & & \\
\hline 5 bicuspid (fig 2) & ? & $\star$ & + & Aortic cusp perforation & $\mathbf{P}$ \\
\hline 6 bicuspid & $?$ & - & + & $\begin{array}{l}\text { Mycotic aneurysm } \\
\text { posterior and } \\
\text { subannular to aorta }\end{array}$ & NP \\
\hline 7 & + & Abnormal MV & + & MV cordal rupture & $\mathbf{P}$ \\
\hline 8 & + & $\begin{array}{l}\text { Mycotic aneurysm } \\
\text { anterior and supra- }\end{array}$ & $\begin{array}{l}+ \\
+\end{array}$ & $\begin{array}{l}\text { Mycotic aneurysm } \\
\text { anterior and supra- }\end{array}$ & $\mathrm{P}$ \\
\hline 9 bicuspid & + & $\begin{array}{l}\text { Aortic cusp } \\
\text { perforation }\end{array}$ & + & $\star$ & $\mathbf{P}$ \\
\hline
\end{tabular}

MV, mitral valve; $P$, performed; NP, not performed. *Aortic cusp perforation missed. 
Table 3 Detection of vegetations or complications or both in patients with prosthetic valve endocarditis

\begin{tabular}{|c|c|c|c|c|c|}
\hline \multirow{2}{*}{$\begin{array}{l}\text { Prosthetic valve } \\
\text { Patient no }\end{array}$} & \multicolumn{2}{|c|}{ Precordial echocardiography } & \multicolumn{2}{|c|}{ Transoesophageal echocardiography } & \multirow[b]{2}{*}{ Operation } \\
\hline & Vegetations & Complications & Vegetations & Complications & \\
\hline $1 \mathrm{M}$ & - & - & + & - & $\mathbf{P}$ \\
\hline $2 \mathrm{M}$ & - & - & + & - & NP \\
\hline $3 \mathrm{~A}$ & - & - & - & Valve dehiscence & $\mathbf{P}$ \\
\hline $4 \mathrm{~A}$ & - & - & - & Valve dehiscence & $\mathbf{P}$ \\
\hline $5 \mathrm{~A}$ & - & - & - & Valve dehiscence & $\mathbf{P}$ \\
\hline $6 \mathrm{~A}$ & - & - & + & $\begin{array}{l}\text { Valve dehiscence and } \\
\text { mycotic aneurysm } \\
\text { posterior and } \\
\text { subannular to aorta }\end{array}$ & $\mathbf{P}$ \\
\hline $7 \mathrm{~A}$ & - & $\begin{array}{l}\text { Abnormal echo } \\
\text { structure in LA? }\end{array}$ & - & $\begin{array}{l}\text { Mycotic aneurysm } \\
\text { posterior and }\end{array}$ & $\mathbf{P}$ \\
\hline $8 \mathrm{~A}$ & - & $\begin{array}{l}\text { Mycotic aneurysm } \\
\text { posterior to aorta }\end{array}$ & - & $\begin{array}{l}\text { Mycotic aneurysm } \\
\text { posterior and } \\
\text { subannular to aorta, } \\
\text { and intramural abscess }\end{array}$ & * \\
\hline $9 \mathrm{MA}$ & - & Mycotic aneurysm & - & Valve dehiscence $(\mathrm{A})$ & $\mathbf{P}$ \\
\hline $10 \mathrm{MAT}$ (fig 1) & - & - & + & Mycotic aneurysm & $\mathbf{P}$ \\
\hline $\begin{array}{l}11 \text { MAT } \\
12 \text { MAT (fig 4) }\end{array}$ & $\begin{array}{l}- \\
-\end{array}$ & $\begin{array}{l}- \\
\text { Mycotic aneurysm } \\
\text { anterior to aorta }\end{array}$ & $\begin{array}{l}- \\
-\end{array}$ & $\begin{array}{l}\text { Valve dehiscence }(\mathbf{M}) \\
\text { Mycotic aneurysm } \\
\text { at the posterior } \\
\text { aortic annulus and } \\
\text { flail Hancock }(M)\end{array}$ & $\begin{array}{l}\mathbf{P} \\
\mathbf{P}\end{array}$ \\
\hline
\end{tabular}

M, mitral prosthesis; A, aortic prosthesis; $T$, tricuspid prosthesis; LA, left atrium; P, performed; NP, not performed; $\star$ Died, no necropsy.

PROSTHETIC VALVE (I 2 PATIENTS, TABLE 3)

Precordial echocardiography did not show any defect in eight patients. In one patient (case 7) an abnormal echo structure was noticed in the left atrium; the cause was not identified. In three patients (cases 8, 9, and 12) a mycotic aneurysm was found anterior to the aortic prothesis. Transoesophageal echocardiography showed vegetations in four patients: in three patients these were attached to the left atrial site of the mitral prosthesis and in one patient at the aortic valve ring. Complications were found in 10 patients: dehiscence of the posterior site of an aortic prosthesis in six; mycotic aneurysm in five; left ventricular free wall abscess in one patient; and a flail leaflet of a Hancock mitral prosthesis in one patient. The echocardiographic findings were confirmed at operation in 10 patients. One patient died (necropsy was not performed), and one patient was successfully treated with antibiotics.

\section{Discussion}

Infective endocarditis is potentially a life threatening disease. The need for operation in

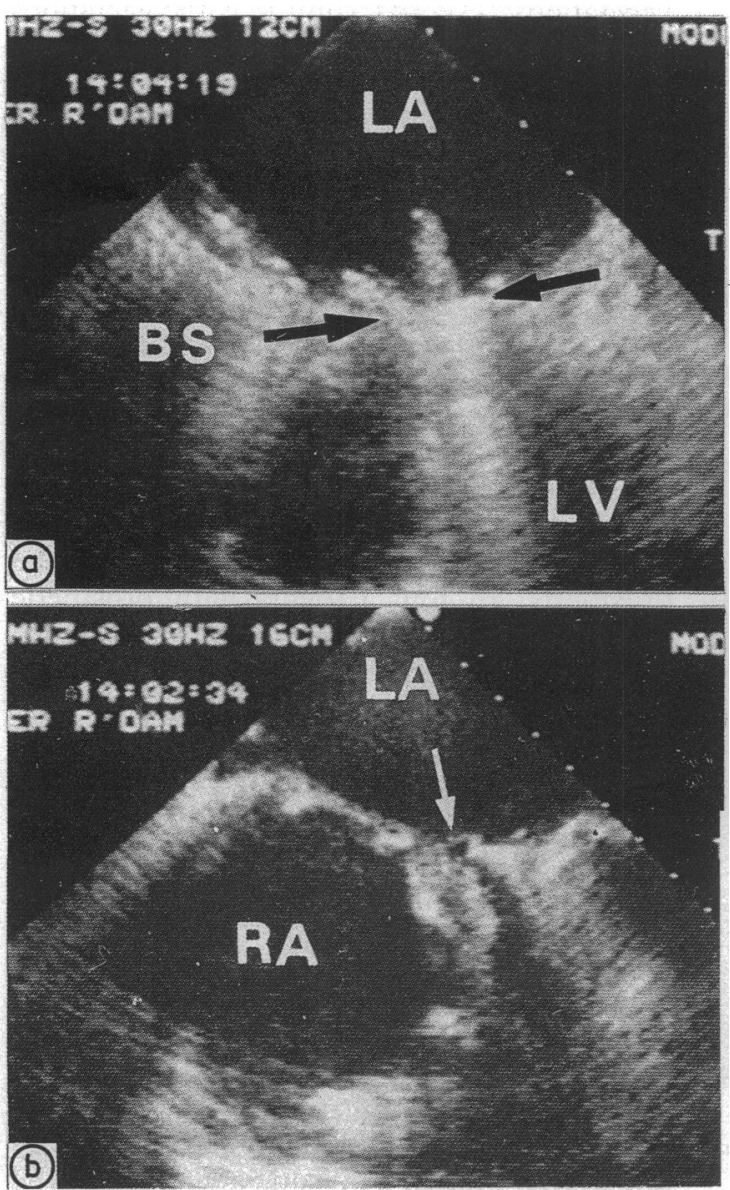

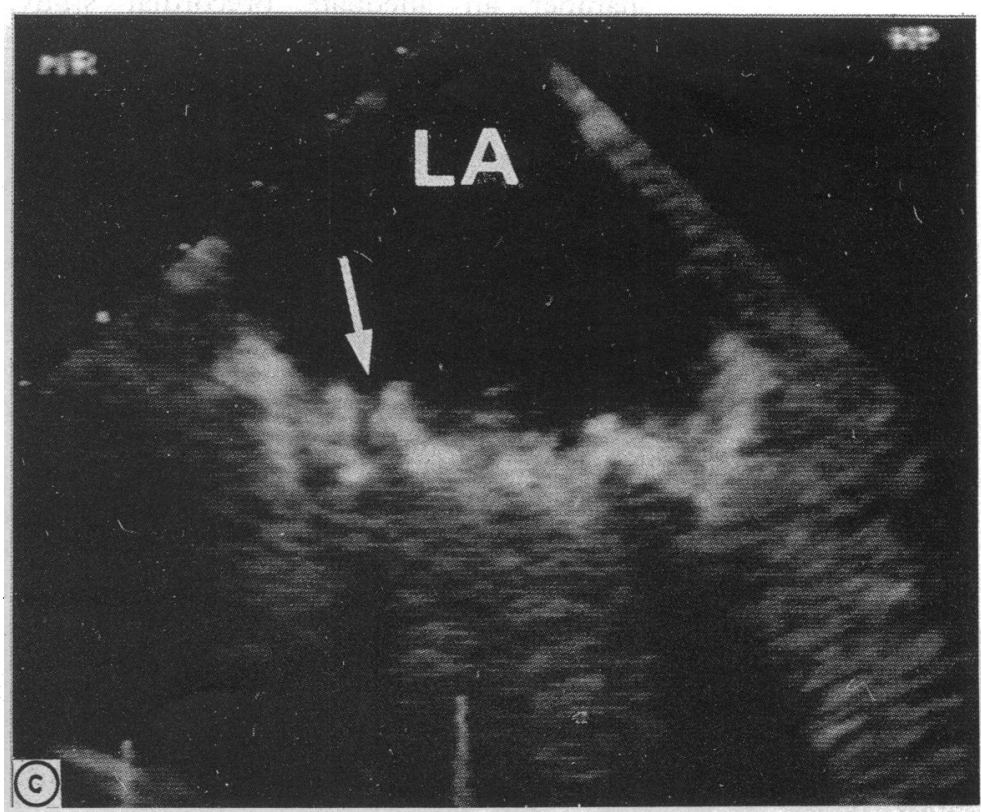

Figure 1 Transoesophageal echocardiographic systolic still frames $(a, b, c)$ from a patient with endocarditis of the mitral Björk-Shiley prosthesis (table 3, case 10). (a) As well as a vegetation attached to the left atrial site of the prosthesis (BS, black arrows), (b) a small and pulsatile mycotic aneurysm was seen at the mitral annulus (arrow). (c) Follow up examination after a period of pulmonary oedema showed a perforation (arrow) of the aneurysm resulting in partial valve dehiscence. This was not detected by precordial echocardiography. LA, left atrium; $L V$, left ventricle; $R A$, right atrium. 
Figure.2 Transoesophageal still frame from a patient with endocarditis of $a$ native aortic valve (table 2 , case 5) showing a perforation in the aortic cusp (arrow) with a vegetation. This was not detected by precordial echocardiography. Ao, aorta; $L A$, left atrium, $L V$, left ventricle. echocardiographic diastolic

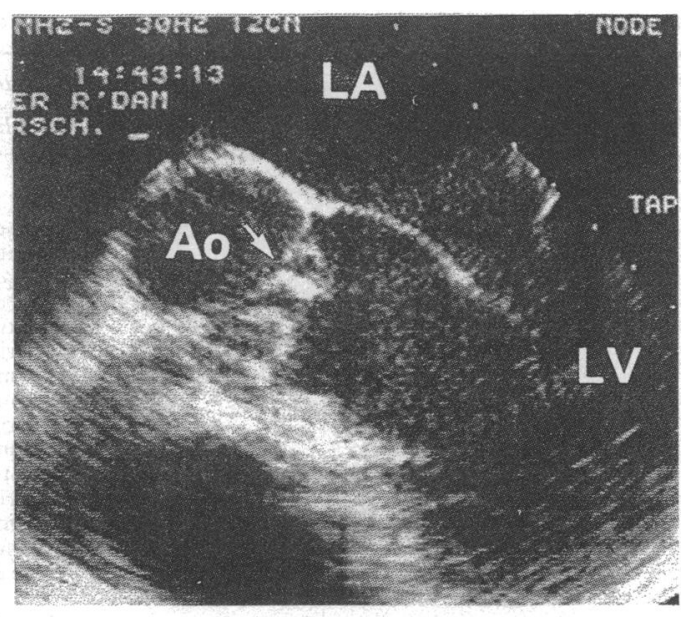

these patients usually indicates that the diagnosis and onset of treatment have been delayed. ${ }^{15}$

The incidence of detectable mycotic aneurysms or abscess formation during life is not known, ${ }^{16}$ but these complications were often found in necropsy series. ${ }^{17-19}$ Because perivalvar infective endocarditis is usually associated with a higher incidence of serious complications, a more complicated surgical procedure, or death ${ }^{1020}$ early diagnosis is essential. ${ }^{22}$ But angiography proved to be of limited value. ${ }^{623}$ Despite increasing experience in precordial echocardiography and the availability of more complex equipment, false negative studies in native valve endocarditis were reported. ${ }^{4-6}$

In patients with prosthetic valve endocarditis, the prosthesis can interfere with the ultrasound beam and ultrasound artefacts can hamper an adequate precordial study. ${ }^{612}$ Limited resolution from the precordium also produced false positive images when there was pre-existing valve disease, which interferes with the precise visualisation of the underlying infectious process and any associated complications. $^{1-3}$

The proximity of the transducer to the heart and avoidance of chest wall interference during transoesophageal echocardiography allows the use of a high frequency beam and this gives images of high resolution ${ }^{24-26}$ showing the precise shape of the cardiac defect.

In all 33 patients in this study with clinically suspected endocarditis transoesophageal echocardiography (with a $5.6 \mathrm{MHz}$ transducer) detected vegetations or complications or both.

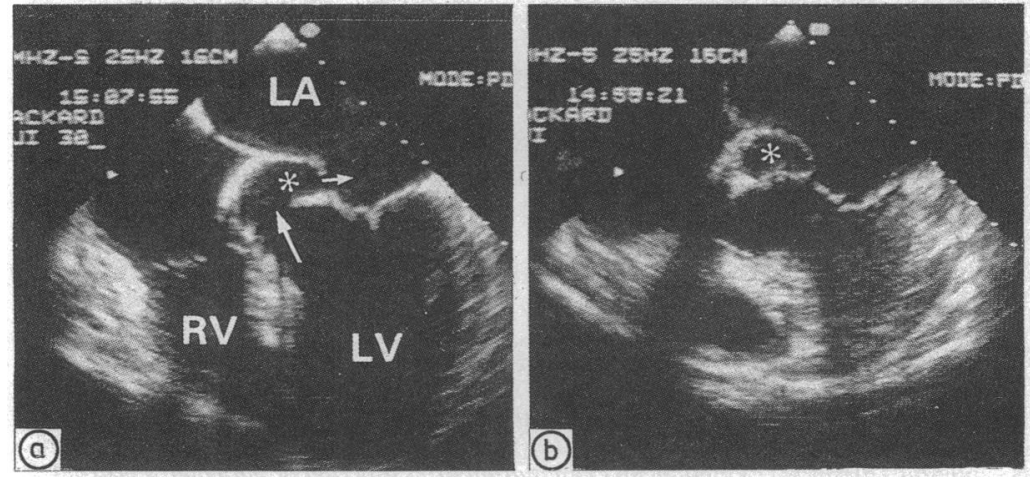

Figure 3 Transoesophageal echocardiographic systolic still frame $(a, b)$ from a patient with endocarditis of the native mitral valve (table 1, case 12). (a) A subannular (to the aortic junction) mycotic aneurysm (asterisk) with a fistulous connection of the left ventricular outflow tract (large arrow) via the aneurysm into the left atrium ( $L A$, small arrow). (b) Slight superior tilting of the transducer showed that there was no communication between the aneurysm and the left ventricle or left atrium. $L V$, left ventricle; $R V$, right ventricle.
Using a $3.5 \mathrm{MHz}$ transoesophageal transducer Daniel and co-workers achieved a detection rate of $85 \% .{ }^{13}$ With precordial echocardiography we detected valve defects in $30 \%$ of patients. Twenty five eventually underwent operation because transoesophageal echocardiography established the diagnosis without preoperative angiography.

The findings at operation show that false positive diagnoses did not occur with transoesophageal echocardiography. The technique failed to show aortic cusp perforation in two patients. The explanation for this may be the combination of the size and position of the perforation within the aortic cusp. Neither medical management nor operation was influenced by the absence of this specific information. Though the information obtained with transoesophageal echocardiography in the eight unoperated patients could not be independently confirmed, the quality of the images meant that an unequivocal diagnosis was possible.

\section{NATIVE VALVE ENDOCARDITIS}

Transoesophageal echocardiography detected many more vegetations in patients with native valve endocarditis $(86 \%)$ than precordial echocardiography $(28 \%)$. Complications too were more often detected with transoesophageal echocardiography $(48 \%)$ than precordial echocardiography $(20 \%)$. Five distinct pathological features in native mitral valve endocarditis were seen only with transoesophageal echocardiography. These were (a) mitral valve stenosis with vegetations; (b) myxomatous degeneration of leaflets with vegetations; $(c)$ cordal rupture with vegetations and $(d)$ without vegetations, and $(e)$ mycotic aneurysm with fistulous connection (fig 3 ).

Similarly, in patients with aortic valve endocarditis high resolution images showed vegetations on a bicuspid aortic valve. The precise origin and outline of mycotic aneurysms were clearly shown.

\section{PROSTHETIC VALVE ENDOCARDITIS}

Transoesophageal imaging showed the defect in all the patients whereas precordial echocardiography was successful in only a third. This is not surprising because when a prosthetic valve is present the transoesophageal approach avoids ultrasonic shadowing by the prosthesis. In four patients with prosthetic valve endocarditis transoesophageal echocardiography detected vegetations that were not depicted by the precordial approach.

Complications at the valve ring of a mitral prosthesis (fig 1) or posterior portion of the aortic prosthesis (fig 4) are well displayed by transoesophageal echocardiography. But in patients with an aortic valve prosthesis the anterior aortic root is best displayed by the precordial approach. This observation is highlighted in two patients (table 3, patients 9 and 12) in whom precordial echocardiography showed evidence of a mycotic aneurysm in front of an aortic prosthesis (fig 4). Transoesophageal echocardiography did not identify this defect, though a mycotic aneurysm in the posterior valve ring was diagnosed only by this technique (fig 4).

Transoesophageal echocardiographic images 


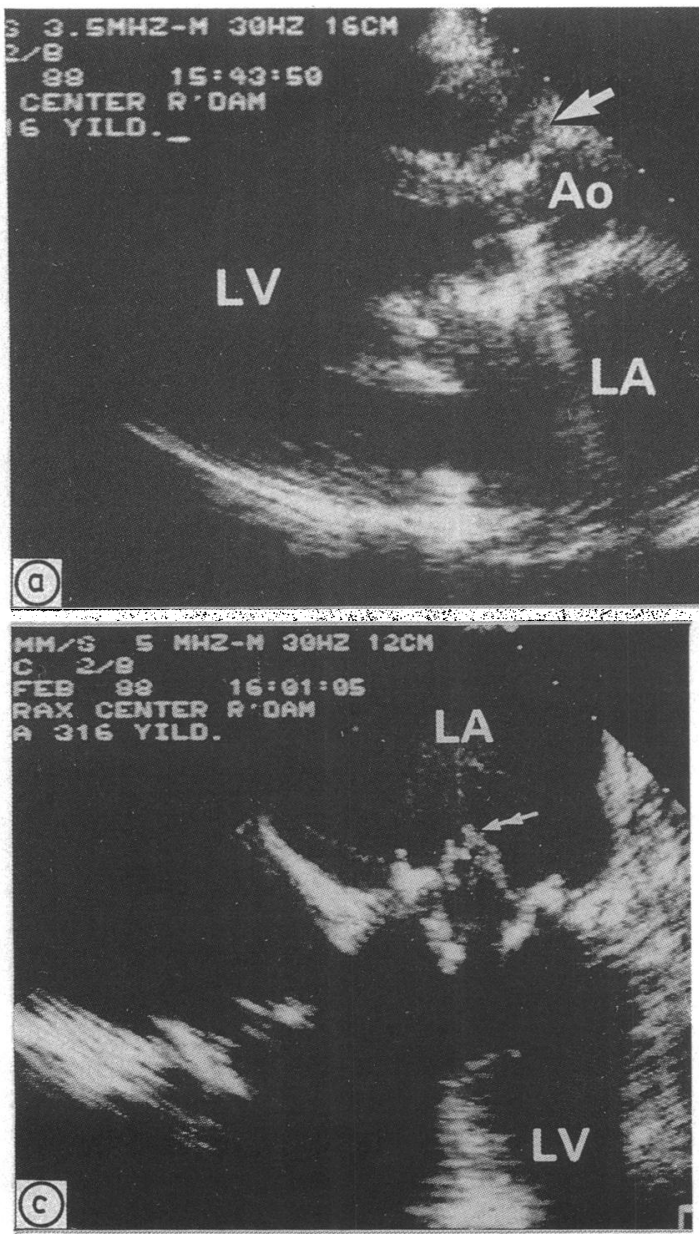

were diagnostic and allowed appropriate decisions about clinical management in all patients. The technique was useful where clinical features suggested endocarditis and precordial echocardiographic imaging was either equivocal or negative. We think that transoesophageal echocardiography is the best diagnostic approach in patients with suspected endocarditis of either a native or prosthetic valve.

This project was supported by a grant from the Interuniversity Cardiology Institute, The Netherlands.

We thank the International Medical, Zutphen, The Netherlands, for secretarial support.

1 Stewart JA, Silimperi D, Harris P, Kent Wise $\mathbf{N}$, Fraker TD, Kisslo JA. Echocardiographic documentation of vegetative lesions in infective endocarditis: clinical implications. Circulation 1980;61:374-80.

2 Melvin ET, Berger M, Lutzker LG, Goldberg E, Mildvan D. Noninvasive methods for detection of valve vegetations in infective endocarditis. Am J Cardiol vegetations in
$1981 ; 47: 271-8$.

3 Brandenburg RO, Giuliani ER, Wilson WR, Geraci JE. Infective endocarditis-a 25 year overview of diagnosis and therapy. J Am Coll Cardiol 1983;1:280-91.

4 Mintz GS, Kotler MN. Clinical value and limitations of echocardiography. Arch Intern Med 1980;140:1022-7.

5 Becher $\mathbf{H}$, Hanrath $\mathbf{P}$, Bleifeld $W$, Bleese $N$. Correlation of echocardiographic and surgical findings in acute bacterial endocarditis. Eur Heart J 1984;5 (suppl C):67-70.

6 Van Herwerden LA, Gussenhoven EJ, Roelandt JRTC, Haalebos MMP, Mochtar B, Ligtvoet KM. Intraoperative two-dimensional echocardiography in
complicated infective endocarditis of the aortic valve. $J$ Thorac Cardiovasc Surg 1987;93:587-91.

7 Neimann JL, Danchin N, Godenier JP, Villemot JP, Faivre G. Two-dimensional echocardiographic recognition of aortic valve ring abscess. Eur Heart J 1984;5 (suppl C): $59-65$.

8 Pollak SJ, Felner JM. Echocardiographic identification of an aortic valve ring abscess. J Am Coll Cardiol 1986;7: 1167-73.

9 Cowgill LD, Addonizio VP, Hopeman AR, Harken AH. A practical approach to prosthetic valve endocarditis. Ann Thorac Surg 1987;43:450-7.

10 Croft CH, Woodward W, Elliott A, Commerford PJ Barnard CN, Beck W. Analysis of surgical versus medical therapy in active complicated native valve infective endocarditis. Am J Cardiol 1983;51:1650-5. Transesophageal two-dimensional echocardiography: its role in solving clinical problems. J Am Coll Cardio 1986;8:975-9.

12 Polak PE, Gussenhoven WJ, Roelandt JRTC. Transoesophageal cross-sectional echocardiographic recognition of an aortic valve ring abscess and a subannular mycotic aneurysm. Eur Heart $J$ 1987;8:664-6.

13 Daniel WG, Schröder E, Nonnast-Daniel B, Lichtlen PR. Conventional and transoesophageal echocardiography in Conventional and transoesophageal echocardiography in (suppl J):287-92.

14 Gussenhoven EJ, Taams MA, Roelandt J, et al. Oesophagea echocardiography. Int J Cardiac Imaging 1987;2:231-9.

15 Westaby S, Oakley C, Sapsford RN, Bentall HH. Surgical treatment of infective endocarditis with special reference to prosthetic valve endocarditis. Br Med J 1983;287: $320-3$.

16 Scanlan JG, Seward JB, Tajik AJ. Valve ring abscess in infective endocarditis: visualization with wide angle two dimensional echocardiography. $A m \quad J$ Cardio 1982;49:1794-800

17 Arnett EN, Roberts WC. Valve ring abscess in active infective endocarditis. Frequency, location and clues to clinical diagnosis from the study of $\mathbf{9 5}$ necropsy patients. Circulation 1976;54:140-5.

18 Arnett EN, Roberts WC. Prosthetic valve endocarditis: clinicopathologic analysis of 22 necropsy patients with comparison of observations in $\mathbf{7 4}$ necropsy patients with active infective endocarditis involving natural left-sided cardiac valves. Am J Cardiol 1976;38:281-92.

19 Anderson DJ, Bulkley BK, Hutchins GM. A clinicopathologic study of prosthetic valve endocarditis in 22 pathologic study of prosthetic valve endocarditis in 22 patients: morphologic basis

20 Ellis SG, Goldstein J, Popp RL. Detection of endocarditisassociated perivalvular abscesses by two-dimensional echocardiography. J Am Coll Cardiol 1985;5:647-53.

21 Sareli P, Klein HO, Schamroth L, et al. Contribution of echocardiography and immediate surgery to the management of severe aortic regurgitation from activ infective endocatis.

22 O'Brien JT, Geiser EA. Infective endocarditis and echocardiography. Am Heart $J$ 1984;108:386-94.

23 Donaldson RM, Westgate C, Bennett JG, Rickards AF. The role of echocardiography in suspected bacterial endocarditis. Eur Heart J 1984;5 (suppl C):53-7.

24 Gussenhoven EJ, van Herwerden LA, Roelandt J, Bos E, de Jong N. Detailed analysis of aortic valve endocarditis: comparison of precordial, esophageal and epicardial twodimensional echocardiography with surgical findings. $J$ Clin Ultrasound 1986;14:209-11.

25 Taams MA, Gussenhoven WJ, Schippers LA, et al. The value of transoesophageal echocardiography for diagnosis of thoracic aorta pathology. Eur Heart J1988;9:1308-16.

26 Taams MA, Gussenhoven WJ, Cornel JH, et al. Detection of left coronary artery stenosis by transoesophageal echocardiography. Eur Heart $J$ 1988;9:1162-6. 